\title{
An Analysis of Multi-Station Ground Observations of VLF Hiss
}

\author{
Lalmani, Manoranjan RAO, V.V. SOMAYAJULU and B.A.P. TANTRY \\ Electronics and Radio Physics Laboratory, \\ Department of Physics, Banaras Hindu University, \\ Varanasi, India \\ (Received February 19, 1972) \\ (Revised April 24, 1972)
}

\begin{abstract}
The possibility that VLF hiss observed at low latitudes is a consequence of waveguide mode propagation of energy from sources located in the auroral zone is examined in some detail. From the locii of the hypothetical point sources which would yield the observed power ratios for any given pair of stations, it is found that sources located in a region around the auroral zone can explain the observations at all stations. It is also shown that the accepted values of the dominant mode attenuation in the terrestrial waveguide can explain the observed hiss spectral densities at low latitudes only if we assume the presence of an extended source along the auroral zone.
\end{abstract}

Of the various types of VLF-emissions, hiss is perhaps the least known phenomenon. Its unstructured character resembling white noise makes its identification on a frequency-time spectrogram rather difficult. Hiss has been observed over a wide range of frequencies from approximately $1 \mathrm{kHz}$ to $500 \mathrm{kHz}$, though its character may differ within this frequency range. Above $2 \mathrm{kHz}$ the occurrence of hiss is maximum in the evening and night sectors (MCINNES, 1961; JORGENSEN, 1966). JORGENSEN (1966) has summarized ground observations of VLF hiss from 13 stations in both hemispheres ranging in geomagnetic latitudes from $34^{\circ}$ to $89^{\circ}$, and has shown that the maximum spectral densities in the frequency range $4-9 \mathrm{kHz}$ vary from $10^{-19}$ to $10^{-14}$ watts $/ \mathrm{m}^{2} / \mathrm{Hz}$. He concludes that hiss comes down through the ionosphere over the auroral zone and then propagates through the earth ionosphere waveguide to lower latitudes. Similarly, ONDOH and IsOzAKI (1965) suggest that their simultaneous hiss observations at Moshiri (geomag. lat: $34^{\circ} \mathrm{N}$ ) and Hiraiso (geomag. lat: $26.2^{\circ} \mathrm{N}$ ) are consistent with the attenuation rates of the dominant mode in the earth ionosphere waveguide. Similar suggestions were made earlier by DowDEN (1961) and ELLIS (1961). 
Evidently, it is desirable to see whether ground based hiss observations at a number of stations covering a reasonably wide range of latitudes could be satisfactorily accounted for by the mode propagation and, if so, to enquire into the physical nature of the sources in the auroral zone. It is precisely with this view that the present investigation was undertaken. Firstly, we calculated the locus of point sources which would yield the observed power ratios for any given pair of stations using the method suggested by DowDEN (1961). The ratio of powers observed at two distances $d_{1}$ and $d_{2}$ from the source can be written as:

$$
\frac{P\left(d_{1}\right)}{P\left(d_{2}\right)}=\frac{d_{2}}{d_{1}} \cdot \exp \left[2 \alpha\left(d_{2}-d_{1}\right)\right]
$$

where $\alpha$ is the attenuation factor.

If we know the ratio of power between two stations, we can draw from Eq. (1) a curve signifying the possible locations of the dipole sources (" point dipoles') provided $\alpha$ is known. This approach was adopted earlier by DOWDEN (1961) and ELLIS (1961). The entire process is repeated for all the stations under study. In Table 1 , we show the maximum spectral densities measured at various stations. For convenience, the southern latitude stations are listed first. In a study of this kind, it would be evidently desirable to have simultaneous measurements at all the stations at the same frequency. A glance at the table shows that this is not the case. If,

Table 1. Observations of VLF Hiss*

\begin{tabular}{|c|c|c|c|c|c|c|}
\hline \multirow{2}{*}{ Station } & \multirow{2}{*}{$\begin{array}{c}\text { Geomag. } \\
\text { lat. }\end{array}$} & $\begin{array}{l}\text { Max. Spect. } \\
\text { density }\end{array}$ & \multicolumn{2}{|c|}{ Observation } & \multirow{2}{*}{\multicolumn{2}{|c|}{ Reference }} \\
\hline & & $\mathrm{W} \cdot \mathrm{m}^{-2}(\mathrm{~Hz})^{-1}$ & Period & Frequency & & \\
\hline Byrd & $70.6^{\circ} \mathrm{S}$ & $1 \times 10^{-13}$ & Jun.-Aug. 1962 & $1-20 \mathrm{kHz}$ & \multicolumn{2}{|c|}{$\begin{array}{l}\text { HELMS and } \\
\text { TURTLE (1964) }\end{array}$} \\
\hline $\begin{array}{l}\text { Macquarie } \\
\text { Island }\end{array}$ & $61.1^{\circ} \mathrm{S}$ & $6.5 \times 10^{-14}$ & $\begin{array}{l}\text { Dec. } 1959- \\
\text { Mar. } 1960\end{array}$ & $4 \mathrm{kHz}$ & DOWDEN & (1961) \\
\hline Hobart & $51.7^{\circ} \mathrm{S}$ & $3 \times 10^{-15}$ & $\begin{array}{l}\text { Dec. } 1959- \\
\text { Mar. } 1960\end{array}$ & $4 \mathrm{kHz}$ & DOWDEN & (1961) \\
\hline Adelaide & $45.0^{\circ} \mathrm{S}$ & $1 \times 10^{-16}$ & Mar.-Aug. 1960 & $4-6 \mathrm{kHz}$ & ELLIS & $(1961)$ \\
\hline Camden & $42.6^{\circ} \mathrm{S}$ & $1 \times 10^{-16}$ & Mar.-Aug. 1960 & $4-6 \mathrm{kHz}$ & ELLIS & (1961) \\
\hline Mundaring & $43.0^{\circ} \mathrm{S}$ & $1.0 \times 10^{-16}$ & Mar.-Aug. 1960 & $4-6 \mathrm{kHz}$ & ELLIS & (1961) \\
\hline Nord & $80.8^{\circ} \mathrm{N}$ & $1 \times 10^{-14}$ & Nov.-Dec. 1964 & $8 \mathrm{kHz}$ & JORGENSEN & (1966) \\
\hline Godhavn & $79.9^{\circ} \mathrm{N}$ & $1 \times 10^{-14}$ & Nov.-Dec. 1964 & $8 \mathrm{kHz}$ & JORGENSEN & $(1966)$ \\
\hline Narssarssuaq & $71.2^{\circ} \mathrm{N}$ & $1 \times 10^{-14}$ & Nov.-Dec. 1964 & $8 \mathrm{kHz}$ & JORGENSEN & (1966) \\
\hline Tromso & $67.1^{\circ} \mathrm{N}$ & $1.5 \times 10^{-15}$ & Aug.-Dec. 1963 & $8 \mathrm{kHz}$ & $\begin{array}{l}\text { HARANG and } \\
\text { LARSEN }\end{array}$ & (1965) \\
\hline Moshiri & $34.3^{\circ} \mathrm{N}$ & $5.4 \times 10^{-18}$ & Jan.-Nov. 1963 & $4-6 \mathrm{kHz}$ & IWAI et al. & $(1964)$ \\
\hline Hiraiso & $26.2^{\circ} \mathrm{N}$ & $4.4 \times 10^{-19}$ & Jun.-Dec. 1966 & $5 \mathrm{kHz}$ & $\begin{array}{l}\text { ONDOH and } \\
\text { ISOZAK }\end{array}$ & I (1968) \\
\hline
\end{tabular}

\footnotetext{
* After Jorgensen (1966).
} 
however, we confine our attention to only the stations in the southern hemisphere we find that all measurements except those at Byrd refer to frequencies between $4-6 \mathrm{kHz}$. Moreover, the periods of measurements at these stations are reasonably close. Thus we choose for our analysis the data recorded at the following stations: Macquarie Island, Hobart, Adelaide, Camden and Mundaring.

Besides being critically dependent on the electron density and collision frequency profiles in the lower ionosphere, the attenuation factor $\alpha$ is also a function of the azimuthal direction of propagation, the nature of the terrain, etc. It is, however, neither possible nor absolutely necessary for our present purpose to give detailed considerations to all these factors. From the theoretical and experimental studies of various authors (e.g., WAIT, 1962; BARR, 1971; CHALLINOR, 1966; FIELD, 1969; CHAPMAN and MACARIO, 1956) we find that a value of $10 \mathrm{db} / 1000 \mathrm{~km}$ is reasonable for the attenuation of the $5 \mathrm{kHz}$ wave. DowDEN (1961), for example, uses a value of $10 \mathrm{db} / 1000 \mathrm{~km}$ for $4 \mathrm{kHz}$.

With the above value of attenuation we have drawn curves showing the possible locations of point sources from Eq. (1) for different combinations of stations. The results are shown in Fig. 1 from which we find that, in general, the curves extend over large distances. The source extent is relatively limited for the high power ratio between two close stations. This is evident from the curve drawn for Macquarie Island and Hobart

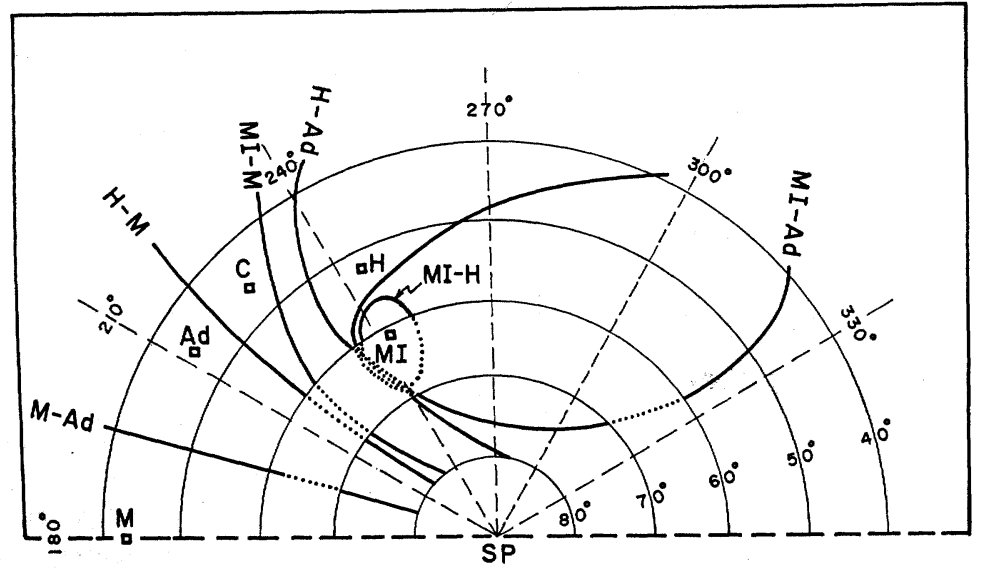

Fig. 1 Showing locations of stations selected for analysis. The coordinates are geomagnetic with SP indicating geomagnetic south pole. MI (Macquarie Island), H (Hobart), Ad (Adelaide), M (Mundaring) and $\mathrm{C}$ (Camden). Thick curves show possible locations of point sources calculated from Eq. (1). Each curve is calculated for a pair of stations and is labelled by combined symbols denoting the two stations. 
denoted by MI-H. An interesting fact emerges from Fig. 1 if we devide the entire hemisphere into latitude zones each of, say, $10^{\circ}$ wide. All the curves pass through the latitude zone between $60^{\circ}$ and $70^{\circ}$. The parts of curves which lie in this latitude range are shown dotted for convenience. Thus it seems likely that hiss sources located in a narrow latitudinal range around the auroral zone can account for observations at all lower latitudes. This is consistent with the experimental observations that hiss zones are the same as the auroral zones of precipitation (JORGENSEN, 1966).

From the observed spectral densities at various stations, it is, in principle, possible to calculate back the attenuation coefficient and to compare the result with the value assumed for locating the point sources. To do this we have to assume the source location. If we assume the source is situated at, say, $65^{\circ}$ latitude and if we measure the minimum distances to different stations from this latitude we find $\alpha=10.5 \pm 1.4 \mathrm{db} / 1000 \mathrm{~km}$. This is in good agreement with the value of $10 \mathrm{db} / 1000 \mathrm{~km}$ assumed for drawing the curves for different combinations of the stations. It therefore follows that the observed variation of VLF hiss intensity is consistent with the dominant mode propagation in the earth ionosphere waveguide only if we assume the presence of a source extending all along a latitude close to the auroral zone. It is expected that a similar conclusion would be reached if the measurements in the northern hemisphere were analysed.

It should finally be pointed out that some low latitude observations (see for example, ONDOH and IsOZAKI, 1965) cannot be explained within the framework of the waveguide mode propagation. A detailed discussion of such observations is, however, beyond the scope of this brief communication.

The research reported here was supported by the National Oceanic and Atmospheric Administration of the United States, under the contract No. : E-33-70 (N).

\section{References}

BARR, R., The Propagation of ELF and VLF radio waves beneath an inhomogeneous anisotropic ionosphere, J. Atmosph. Terr. Phys., 33, 343-353, 1971.

CHALLINOR, R.A., The phase velocity and attenuation of audio frequency electromagnetic waves from simultaneous observations of atmospherics at two spaced stations, $J$. Atomosph. Terr. Phys., 29, 803-810, 1966.

CHAPMAN, F.W. and R.C.V. MACARIo, Propagation of audio frequency waves to great distances, Nature, 177, 930, 1956.

DowDEN, R.L., Simultaneous observations of VLF noise ('hiss') at Hobart and Macquaric Island, J. Geophys. Res., 66, 1587-1588, 1961.

ELLIS, G.R.A., Spaced observations of the low frequency radiation from the earth's upper atmosphere, J. Geophys. Res., 66, 19-23, 1961. 
FIELD, E.C., Propagation of ELF waves under normal and naturally disturbed conditions, $J$. Geophys. Res., 74, 3639-3650, 1969.

HARANG, L. and R. LARSEN, Radio wave emission in the VLF band observed near the auroral zone, 1, Occurrence of emissions during disturbances, J. Atmosph. Terr. Phys., 27, 481-497, 1965.

Helms, W.J. and J.P. TURTLE, A cooperative report on correlation between auroral, magnetic, and ELF phenomena at Byrd station, Antarctica, Stanford Electronics Lab., Tech. Rept., 3408-2, 1964.

IwaI, A., J. OUtsu and Y. TANaka, The observations of VLF emissions at Moshiri, Proc. Res. Inst. Atmospherics Nagoya Univ., 11, 29-40, 1964.

JORGENSEN, T.S., Morphology of VLF hiss zones and their correlation with particle precipitation events, J. Geophys. Res., 71, 1367-1375, 1966.

JORGENSEN, T.S., Interpretation of auroral hiss measured on OGO2 and at Byrd station in terms of incoherent Cerenkov radiation, J. Geophys. Res., 73, 1055-1069, 1968.

MCINNEs, B.A., A study of ionospherics at Macquarie Island, Australian J. Phys., 14, 218-33, 1961.

ONDOH, T. and S. IsOZAKI, Observation of VLF hiss at Hiraiso, Japan, Report of Ionosphere and Space Res., 19, 225-230, 1965.

ONDOH, T. and S. IsOzAKr, Characteristics of low latitude VLF emissions, J. Radio Res. Lab., 15, 133-146, 1968.

WaIT, J.R., Electromagnetic waves in stratified media, Pergamon Press, Oxford, 1962. 